\title{
Prevalence of multi-drug resistant Staphylococci isolated from surgical site infections
}

\author{
Hisham A. Abbas, Ghada H. Shaker, Wael A.H. Hegazy, Amr A. Baiomy* \\ Zagazig University, Faculty of pharmacy, Department of microbiology and Immunology \\ *Corresponding author e-mail: amr_elhalawaty@yahoo.com
}

\begin{abstract}
Surgical site infections are the most common post-operative infections even in hospitals with most modern facilities complications and standard protocols of pre-operative preparation and antibiotic prophylaxis.

Staphylococci stay as our natural flora and yet sometimes threaten our life as tenacious pathogens. In addition to their ability to evade our immune system, the multi-drug resistance phenotype makes Staphylococci the most intractable pathogenic bacteria in the history of antibiotic chemotherapy. Staphylococci are among the leading causes of nosocomial infections such as surgical site infections. Increasing resistance to $\beta$-lactams and the glycopeptides complicates treatment of infections caused by Stahpylococci. The aim of this study is to investigate the antibiotic resistance profile of Staphylococci isolated from surgical site infection.

Staphylococci isolates were identified morphologically, by Gram stain and biochemical tests. Antimicrobial susceptibility testing was done by the Kirby-Bauer standard disk diffusion method. One hundred Staphylococci isolates were recovered from one hundred and ninety samples isolated from surgical site infections. Staphylococcus aureus was the most predominant one. From 100 isolates, Staphylococcus aureus was found in 91 isolate and coagulase-negative Staphylococci (CoNS) in 9 isolates. Staphylococcus aureus isolates were highly resistant to tigecycline, oxacillin, ampicillin and ampicillin-sulbactam antibiotics. They showed intermediate resistance to daptomycin, amikacin, azithromycin, levofloxacin, clindamycin, sulfamethoxazole-trimethoprime, doxycycline and gatifloxacin, while they showed low resistance to vancomycin, linezolid and imipenem. On the other hand, CoNS isolates were highly resistant to doxycycline, oxacillin, ampicillin and ampicillin- sulbactam antibiotics. They showed intermediate resistance to daptomycin, levofloxacin, clindamycin, sulfamethoxazoletrimethoprime, gatifloxacin, vancomycin, tigecycline, linezolid and imipenem, while they showed low resistance to amikacin and complete sensitivity to azithromycin. Eighty four isolates were multi-drug resistant.

Percentage of multi-drug resistant Staphylococci isolates were very high. This may be attributed to the misuse of antibiotics. To minimize resistance, strict antimicrobial prescription policy should be applied.
\end{abstract}

Keywords: Staphylococci, Multi-drug resistance, surgical sites

\section{INTRODUCTION}

Surgical site infections (SSIs) are defined as infections of skin or underlying soft tissues at the surgical site occurring within 30 days, following National Healthcare Safety Network (NHSN) operative procedure, in which an incision was closed primarily (CDC, 2013). There are three types of SSI; superficial incisional, deep incisional and organ/space SSI (CDC, 2013). In clean surgeries methicillin resistant Staphylococcus aureus (MRSA) is the most predominant, while coagulase negative Staphylococci (CoNS), Enterococci and Streptococci are involved less frequently (Suchitra and Lakshmidevi, 2013). Resistance to the chemotherapeutic antimicrobial agents is broadly classified as occurring via either intrinsic (innate) resistance or acquired resistance by horizontal gene transfer or vertical gene transfer (Vranakis et al., 
2014). Bacteria can resist the antimicrobial agents by active efflux systems and changes in cell permeability, conversion from a planktonic life cycle to a sessile biofilm life cycle, inactivation or enzymatic modification and/or alteration of antibiotic target (Alekshun and Levy, 2007). Multi-drug resistance suggests the presence of efflux pump ( $\mathbf{L i}$ and Nikaido, 2009). Active efflux is now known to play a major role in the resistance of many bacterial species to antimicrobial agents(Ahmed et al., 2013). Bacterial efflux systems are examples of larger classes of transporters involved in the uptake of essential nutrients and ions, excretion of metabolic end products, deleterious substances and communication between cells and the environment ( $\mathbf{L i}$ and Nikaido, 2004).Efflux pumps in Grampositive bacteria belong to four unrelated families: major facilitator superfamily (MFS), small multi-drug resistance (SMR), multi-drug and toxic extrusion (MATE), and adenosine triphosphate (ATP)-binding cassette (ABC) (Handzlik et al, 2013).

The objective of this study is to investigate the multi-drug resistance of Staphylococci isolated from surgical site infections.

\section{MATERIALS and METHODS \\ Bacterial strains}

One hundred Gram positive Staphylococci isolates were recovered from 190 specimens from patients with SSI admitted to Surgery Department in Zagazig University Hospitals, Egypt.

\section{Media and chemicals}

Antibiotic disks were obtained from Oxoid (Hampshire, England). These disks include ampicillin (AM, $10 \mu \mathrm{g}$ ), ampicillin-sulbactam (SAM, $20 \mu \mathrm{g}$ ), doxycycline (DO, $30 \mu \mathrm{g}$ ), tigecycline (TGC, $15 \mu \mathrm{g}$ ), gatifloxacin (GAT, $5 \mu \mathrm{g}$ ), azithromycin (AZM, $15 \mu \mathrm{g}$ ), imipenem (IPM, $10 \mu \mathrm{g}$ ), linzeolid (LZD, $30 \mu \mathrm{g}$ ), vancomycin (VA, $30 \mu \mathrm{g}$ ), clindamycin (DA, $2 \mu \mathrm{g}$ ), daptomycin (DAP, $30 \mu \mathrm{g}$ ), sulfamethoxazole-trimethoprim
(SXT,25 $\mu \mathrm{g}), \quad$ amikacin $\quad(\mathrm{AK}, 30 \mu \mathrm{g})$, levofloxacin (lev, $5 \mu \mathrm{g}$ ), vancomycin (VA, $30 \mu \mathrm{g})$, oxacillin (OX, $30 \mu \mathrm{g})$. The culture media Mueller Hinton (MH) agar and broth, Tryptone soya agar, Nutrient agar and broth, Mannitol salt agar and agar in dehydrated form were obtained from Oxoid (Hampshire, England).

\section{Isolation and identification}

Specimens were collected from patients with SSI admitted to Surgery Department in Zagazig University Hospitals, Zagazig, Egypt by using sterile cotton swab. After collection, swabs were seeded onto the surface of each of nutrient agar, blood agar and Mannitol salt agar plates then incubated at $37^{\circ} \mathrm{C}$ for 24 hours (Winn and Koneman, 2006).

Bacterial isolates were picked from agar plates and presumptively identified by Gram stain, colony morphology and biochemical characters according to standard microbiological techniques (Winn and Koneman, 2006). These tests were catalase, oxidase, coagulase, hemolysis on blood agar, mannitol fermentation and gelatin liquefaction tests.

Antimicrobial susceptibility testing

Antimicrobial susceptibility testing was done by Kirby-Bauer standard disk diffusion method. Three to five wellisolated colonies were touched with a sterile loop from an overnight agar plate culture and the growth was transferred into $5 \mathrm{ml}$ of $\mathrm{MH}$ broth. The broth culture was incubated at $37^{\circ} \mathrm{C}$ with shaking for 4 to 6 hours. Turbidity was adjusted with sterile broth to obtain turbidity optically comparable to that of 0.5 McFarland standard. This results in a suspension containing approximately $1.5 \times 10^{8}$ $\mathrm{CFU} / \mathrm{ml}$. Within 15 minutes of preparing the adjusted inoculum, a sterile cotton swab was dipped into the inoculum, rotated several times and pressed firmly on the inside wall of the tube. The swab was streaked over the entire surface of the $\mathrm{MH}$ agar plate. The inoculated plates were left on a flat level surface undisturbed for 3-5 minutes. The antibiotic disks were placed 
on the plates and lightly pressed into the agar. The disks were arranged at $15 \mathrm{~mm}$ from edge of the Petri dish and $30 \mathrm{~mm}$ from each other. The plates were incubated inverted at $37^{\circ} \mathrm{C}$ for $18 \mathrm{hr}$. The diameters of the inhibition zones were measured in $\mathrm{mm}$, and interpreted as resistant, intermediate or susceptible (CLSI, 2013).

\section{RESULTS}

Identification of bacterial strains

One hundred Staphylococci

isolates were obtained. Ninety one isolates were Staphylococcus aureus and nine were CoNS. The isolates were Gram positive cocci in bunches. They were confirmed biochemically as shown in table 1.

Table 1: Biochemical identification of Staphylococcus aureus \& CoNS.

\begin{tabular}{|l|c|c|}
\hline Biochemical Test & Staph. aureus & CoNS \\
\hline Catalase & + & + \\
\hline Oxidase & - & - \\
\hline Coagulase & + & $\gamma$-hemolysis \\
\hline Hemolysis on blood agar & $\beta$-hemolysis & - \\
\hline Mannitol fermentation & + & - \\
\hline Gelatin liquefaction & + & white colonies \\
\hline Pigmentation on nutrient agar & Golden yellow pigmentation & and \\
\hline
\end{tabular}

Antimicrobial susceptibility profile

As shown in table 2, the isolates showed varied susceptibility to different antibiotics . Staphylococcus aureus isolates were highly resistant to tigecycline, oxacillin, ampicillin and ampicillinsulbactam. They showed intermediate resistance to daptomycin, amikacin, azithromycin, levofloxacin, clindamycin, sulfamethoxazole-trimethoprime, doxycycline and gatifloxacin. On the other hand, they showed low resistance to vancomycin, linezolid and imipenem. CoNS isolates were highly resistant to doxycycline, oxacillin, ampicillin and ampicillin- sulbactam. They showed intermediate resistance to daptomycin, levofloxacin, clindamycin, sulfamethoxazole-trimethoprime, gatifloxacin, vancomycin, tigecycline, linezolid and imipenem, while they showed low resistance to amikacin and completely sensitive to azithromycin.

Table 2. Antibiotic resistance profile of Staphylococci isolates.

\begin{tabular}{|l|c|c|}
\hline Antibiotic name & $\begin{array}{c}\text { No. (\%) of resistant } \\
\text { Staphylococcus aureus }\end{array}$ & $\begin{array}{c}\text { No. (\%) of resistant } \\
\text { CoNS }\end{array}$ \\
\hline Daptomycin & $26(28.6)$ & $3(33.3)$ \\
\hline Amikacin & $21(23.1)$ & $1(11.1)$ \\
\hline Azithromycin & $25(27.5)$ & $0(0)$ \\
\hline Levofloxacin & $30(33)$ & $4(44.4)$ \\
\hline Clindamycin & $53(58.2)$ & $2(22.2)$ \\
\hline Sulfamethoxazole-trimethoprim & $43(47.3)$ & $5(55.6)$ \\
\hline Doxycycline & $23(25.3)$ & $6(66.7)$ \\
\hline Gatifloxacin & $30(33)$ & $3(33.3)$ \\
\hline Vancomycin & $9(9.9)$ & $3(33.3)$ \\
\hline Tigecycline & $91(100)$ & $4(44.4)$ \\
\hline Linezolid & $15(16.5)$ & $2(22.2)$ \\
\hline Oxacillin & $86(94.5)$ & $8(88.9)$ \\
\hline Ampicillin & $87(95.6)$ & $8(88.9)$ \\
\hline Ampicillin-Sulbactam & $71(78)$ & $6(66.7)$ \\
\hline Imipenem & $10(11)$ & $2(22.2)$ \\
\hline
\end{tabular}


Zagazig J. Pharm. Sci. June, 2018

Vol. 27, Issue 1, pp. 31- 38

Multi-drug resistance is defined as the resistance of microorganism to at least one member in three or more different categories of antibiotics (Alanis, 2005). High rate of multi-drug resistance was found in this study. Multi-drug resistant Staphylococcus aureus represented $83.5 \%$ of isolates while $88.9 \%$ of CoNS were multi-drug resistant.

\section{DISCUSSION}

Surgical site infections are considered among the common healthcareassociated infection (HAIs), accounting for $31 \%$ of all HAIs among hospitalized patients (Magill, 2012). Despite advances in infection control practices such as improved operating room ventilation, sterilization methods, barriers, surgical technique, and antimicrobial prophylaxis, SSIs are still an important cause of morbidity, prolonged hospitalization and mortality(Awad, 2012). SSI is associated with a mortality rate of $3 \%$, and $75 \%$ of SSI-associated deaths are directly attributable to the SSI (Awad, 2012).

Among the Gram-positive cocci, methicillin resistant Staphylococcus aureus and CoNS (MRSA \&MRCoNS) respectively are the most important nosocomial pathogens (Chambers, 2001). Sensitivity of MRSA and MRCoNS to only a few antibacterial agents limits therapeutic options and poses a threat to the patient life (Naqvi et al., 2007).

In the current study, Staphylococcus aureus and CoNS represents $48 \%$ and $0.05 \%$ of all collected specimens respectively. Also, positive cultures were found in $97.3 \%$ of specimens collected from patients. This finding was similar to that observed previously (Agnihotri $\boldsymbol{e t}$ al., 2004; Mehta et al., 2007). This may be attributed to the fact that the normal barrier function of the skin is impaired due to injury, thus allowing microbial colonization and contamination of the wounds that are almost unpreventable even with the use of topical antimicrobial agents (Awad, 2012).
ISSN 1110-5089

ISSN (on-line) 2356_9786

The Staphylococci recovered from patients were identified as Staphylococcus aureus $(91 \%)$ and CoNS (9\%). Most of these bacteria are normal flora in healthy person and they can easily disseminate and cause infection when they get breaks on skins and soft tissue in any of mechanical cases (Chambers, 2001). Moreover, these bacteria are commonly found in the hospital environment, which might increase wound infection rate and crosscontamination among admitted patients

(Khanal and Jha, 2010).

In this study, Staph. aureus was the most predominant organism recovered from patients. This result was similar to that reported in other studies (Ahmed $\boldsymbol{e t}$ al., 2014). Staphylococcal infections are very serious and among the most frequently occurring of all antibioticresistant threats (CDC, 2013). Moreover, resistance to anti-MRSA agents usually occurs through bacterial mutation (Rossolini et al., 2014).

In the current study, Staphylococci isolates showed high resistance to tested $\beta$ lactams. In accordance with our findings, the studies conducted by Ahmed et al., 2013 and Perween et al., 2015 reported the absolute resistance of Staphylococci isolates to $\beta$-lactams.

In this study, Staphylococcus aureus was highly resistant to tigecycline, while CoNS showed intermediate resistance in contrast to the finding observed by Mewara et al., 2014 in which there was no resistance for Staph. aureus . Moreover, $27.5 \%$ of Staph. aureus isolates were resistant to azithromycin, which is higher than that reported previously (El Nakeeb et $\boldsymbol{a l} ., 2014)$ where $21 \%$ of isolates were resistant. Furthermore, Staph. aureus and CoNS isolates exhibited intermediate resistance to daptomycin. This was higher than that observed by Mewara et al. (2014).

In the current study, Staphylococcus aureus and CoNS showed low and intermediate resistance to imipenem $(11 \%$ and $22.2 \%$ ), respectively, which were 
higher than that reported by Abdelkarim et al. (2016) who reported a resistance rate of $3.9 \%$ to imipenem.

In addition, Staph.aureus isolates were of low resistance to linezolid $(16.5 \%)$ that is in accordance with a study performed in Menoufia University Hospitals by Salem and Mahmoud (2014) in which resistance rate was $1.5 \%$ only. On the other hand, CoNS isolates showed intermediate resistance to linezolid which is higher than that observed in previous study (Gabr $\boldsymbol{e t}$ al., 2016 ) where no resistance to linezolid was found.

Staph. aureus and CoNS in this study showed low and intermediate resistance to vancomycin $\quad(9.9 \%$ and $33.3 \%$, respectively). These rates were higher than that reported by Abdelkarim et al. (2016) where there was no resistance to vancomycin. Moreover, intermediate resistance to sulfamethoxazoletrimethoprime was found in all Staphylococci isolates, which is lower than that reported by Salem and Mahmoud, 2014 in which resistance was $88.2 \%$ and higher than that found by Abdelkarim et al. (2016) where $36 \%$ of Staphylococci isolates were resistant .

Staphylococcus resistance to clindamycin observed in this study was in accordance with that reported by Abdelkarim et al. (2016) in which clindamycin resistance was $44 \%$. This study detected intermediate resistance of Staph. aureus and high resistance of CoNS to doxycycline. These results were compatible with Abdelkarim et al. (2016) which reported high resistance to all Staphylococcal isolates (66\%). Futhermore, this study detected intermediate resistance of Staph. aureus and CoNS to gatifloxacin $(33 \%$ and $33.3 \%$ ), respectively. This was in accordance with the results reported by Gabr et al. (2016) in which the resistance of Staph. aureus and CoNS were $41 \%$ and $34.5 \%$, respectively.

Intermediate resistance was also found against both levofloxacin and amikacin.

\section{ISSN (on-line) 2356_9786}

These results were compatible with those of Gabr et al., 2016 In the current study, MRSA and MRCoNS isolates represented high rates of multidrug resistance, which were $83.5 \%$ and $88.9 \%$, respectively. These results were compatible with (Song et al., 2001; Ahmad et al., 2013)

Multi-drug resistance to antibiotics has become a serious concern for the public health setting( Gabr et al., 2016). The role that efflux systems play in antibiotic resistance in MDR bacteria is an important subject that has been extensively discussed in recent years (Bhardwaj, 2012). Although high-level resistance may not occur as a result of MDR efflux pumps alone, the association of over-expression of specific genes among highly resistant clinical isolates cannot be ignored (Piddock, 2006). Synergic increases in resistance seen with over-expression of efflux systems, as well as target site mutations can lead to highly resistant bacteria that are difficult to treat with the antibiotics that are currently available (Bhardwaj, 2012). Efflux is suspected to be the mechanism of antibiotic resistance when there is a simultaneous increase in the MICs of three or more antibiotics for a particular bacterium compared with the MICs of these antibiotics for the parent strain (Poole, 2004). The antibiotic resistance crisis may be attributed to the overuse and misuse of these medications, as well as a lack of new drug development by the pharmaceutical industry due to high cost and challenging regulatory requirements (Gould and Bal, 2013). Incorrectly prescribed antibiotics also contribute to the promotion of resistant bacteria( Gabr et al., 2016). Studies have shown that treatment indication, choice of agent, or duration of antibiotic therapy is incorrect in $30 \%$ to $50 \%$ of cases (CDC, 2013).

In conclusion, this study suggests the application of a strict antibiotic dispensing policy that is based on sensitivity testing and decreasing the use of broad spectrum 
Zagazig J. Pharm. Sci. June, 2018

Vol. 27, Issue 1, pp. 31- 38

antibiotics in order to decrease the emergence of multi-drug resistant Staphylococci.

\section{REFERENCES}

Abdel-karim, S. A.; Serry F. M.; M.Elmasry, E. (2016). Study of azalides and macrolides resistance among clinical isolates of gram positive cocci. Zagazig University. Master thesis

Agnihotri, N.; Gupta, V.; Joshi, R. (2004). Aerobic bacterial isolates from burn wound infections and their antibiograms - a five-year study. Burns, 30(3): 241-243.

Ahmad, B., Urbas, F., Jamil, J., Ahmed, J., and Bashir, S. (2013). Biocides susceptibility pattern and phenotypic detection of Efflux pump in Staphylococcus aureus isolates from two tertiary hospitals of Pakistan. African Journal of Microbiology Research, 7(25): 3171-3178.

Ahmed, E. F.; Gad, G. F.; Abdalla, A. M; Hasaneen, A. M. andAbdelwahab, S. F. (2014). Prevalence of methicillin resistant Staphylococcus aureus among Egyptian patients after surgical interventions. Surg Infect (Larchmt), 15(4): 404-411.

Alekshun, M. N.; Levy, S. B. (2007). Molecular Mechanisms of Antibacterial Multi-drug Resistance. Cell, 128(6): 1037-1050.

Awad, S.S. (2012). Adherence to surgical care improvement project measures and post- operative surgical site infections. Surgical Infection (Larchmt), 13(4): 234-7.

Bhardwaj, A.K.; Mohanty P. .(2012). Bacterial Efflux Pumps Involved in Multidrug Resistance and their Inhibitors: Rejuvenating the Antimicrobial Chemotherapy. Recent Pat Antiinfection Drug Discovery; 7: 73-89.

Centers for Disease Control and Prevention (2013). Office of
ISSN 1110-5089

ISSN (on-line) 2356_9786

Infectious Disease Antibiotic resistance threats in the United States

Chambers , H. F. (2001). The changing epidemiology of Staphylococcus aureus. Emerging Infect Dis, 7, 2001, 178-82.

Clinical and Laboratory Standards Institute (2013). Performance standards for antimicrobial susceptibility testing, $17^{\text {th }}$ informational supplement. CLSI Document M100-S23. Wayne, USA

Col Lavan Singh, A.; Col M.P.; Cariappa, N.K. (2016). Drug sensitivity pattern of various Staphylococcus species isolated at a tertiary care hospital. Medical Journal Armed Forces India, 72, S62-S66.

El Nakeeb, E. A. G.; Ghazal, A. A. E.; Metwalli, D. E .(2014). Detection of inducible clindamycin resistance in staphylococcus aureus. Alexandria University. Master Thesis.

Gabr, I. M., Shaker G. H.; Elmasry E. M.; and Abbas H. A. (2016). Studies on multidrug resistant bacteria isolated from burn wound infections. Zagazig University. Master thesis.

Gould, I.M ; Bal, A.M. (2013). New antibiotic agents in the pipeline and how they can overcome microbial resistance. Virulence. 4(2):185-191.

Handzlik, J.; Matys, A.; KiećKononowicz, K. (2013). Recent advances in multi-drug resistance (MDR) efflux pump inhibitors of Gram-positive bacteria Staph. aureus. Antibiotics, 2(1): 28-45.

Khanal, L. K.; Jha, B. K. (2010). Prevalence of methicillin resistant Staphylococcus aureus (MRSA) among skin infection cases at a hospital in Chitwan, Nepal. Nepal Med Coll J., 12, 224-228.

Li, X. Z.; Nikaido, H. (2004). Effluxmediated drug resistance in bacteria. Drugs, 64(2): 159-204.

Li, X. Z.; Nikaido, H. (2009). Effluxmediated drug resistance in bacteria, an Update. Drugs, 69(12), 1555-1623. 
Magill, S.S. (2012). "Prevalence of healthcare-associated infections in acute care hospitals in Jacksonville, Florida". Infection Control Hospital Epidemiology, 33(3): 283-91.

Mehta, M.; Dutta, P.; Gupta, V. (2007). Bacterial isolates from burn wound infections and their antibiograms: A eight-year study. Indian Journal of Plastic Surgery, 40(1): 25-34.

Mewara, A.; Gautam, V.; Kaur, H.; and Ray, P. (2014). In vitro evaluation of antibiotics for methicillin-resistant Staphylococcus aureus from north India. The Indian journal of medical research, 139(2): 319-327.

Naqvi, Z.; Hashmi, K.; Kharal, S. (2007). Methicillin resistant Staphylococcus aureus (MRSA) in burn patients. PakistanJournal of Pharmacology, 24,7-11.

Perween, N.; Prakash, S. K.; Siddiqui, O. (2015). Multi Drug Resistant Klebsiella Isolates in Burn Patients: A Comparative Study. Proteus, 71, 8(4): 14-17.

Piddock , L.J. (2006). Clinically relevant chromosomally encoded multi-drug resistance efflux pumps in bacteria. Clinical Microbiology ; 19: 382-402

Poole, K. (2004). Efflux mediated multiresistance in Gram negative bacteria.
ISSN (on-line) 2356_9786

Clinical Microbiology Infection. 10, 12-26

Rossolini, G.M.; Arena, F.; Pecile, P.; and Pollini, S. (2014) Update on the antibiotic resistance crisis. Clinical Pharmacology ; 18:56-60.

Salem, E. H. M.; Mahmoud, A. B. (2014). Phenotypic and molecular characterization of Staphylococcus aureus and coagulase negative Staphylococci isolates from Menofia University Hospitals. Menofia University. Ph.D.Thesis.

Song, W.; Lee, K. M.; Kang, H. J.; Shin, D. H.; and Kim D. K. (2001). Microbiologic aspects of predominant bacteria isolated from the burn patients in Korea. Burns, 27(2): 136139.

Suchitra, J.B.; Lakshmidevi, N. (2013). Surgical site infection (SSI) event. CDC.

Vranakis, I.; Goniotakis, I.; Psaroulaki, A. Sandalakis, V.; Tselentis, Y.; Gevaert, K.; and Tsiotis, G. (2014). Proteome studies of bacterial antibiotic resistance mechanisms. Journal of Proteomics, 97(5): 88-99.

Winn, W. C.; Koneman, E. W. (2006). Koneman's Color Atlas and Textbook of Diagnostic Microbiology: Lippincott Williams Wilkins.

\section{انتشار الميكروبات العنقوديه ذات المقاومه المتعدده للأدويه المعزوله من عدوى المواضع الجراحيه}

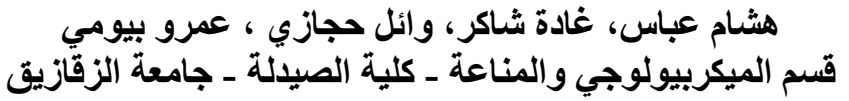

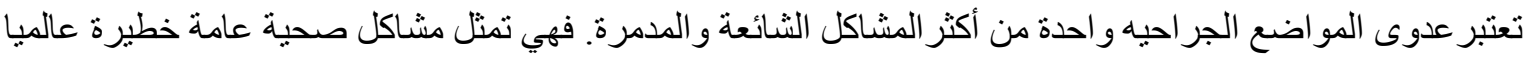

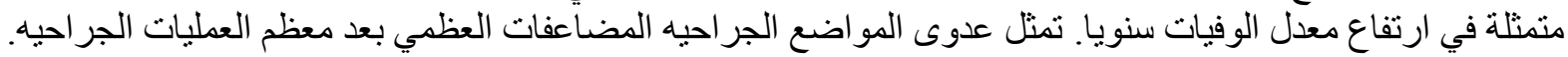

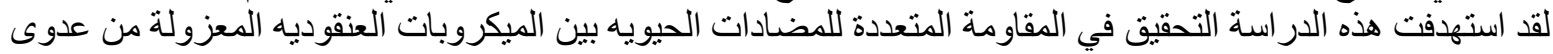

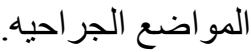

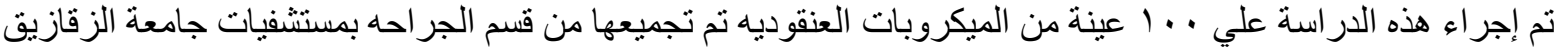

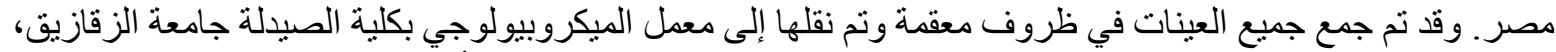
حيث تم التعامل معها على الفور .هذا وكانت الميكروبات المعزولة هي استفيلوكوكس أوريس ( (9\%)و استفيلوكوكس

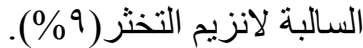

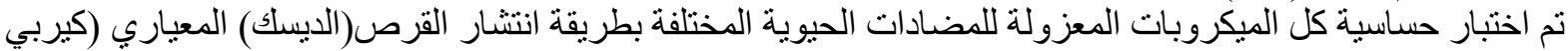

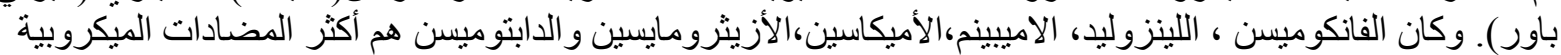




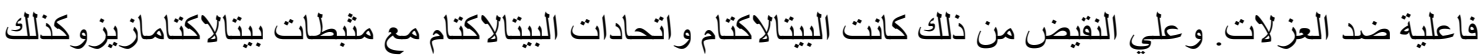

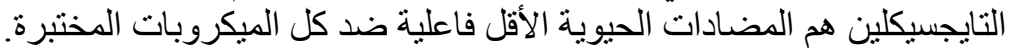

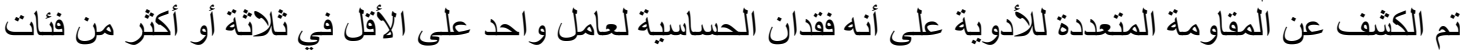

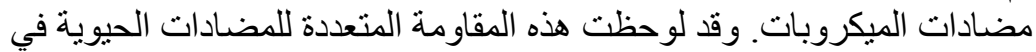

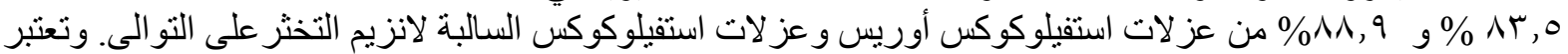

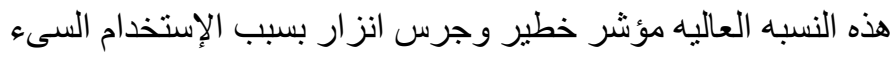

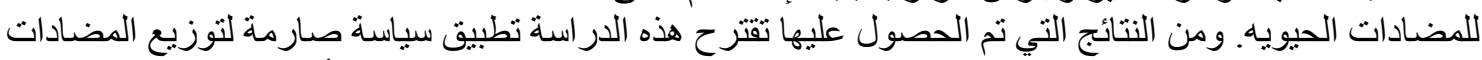

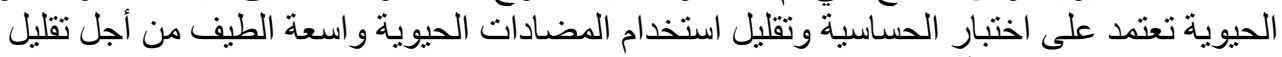
ظهور مقاومة متعددة للأدوية الحية 